№. $4454 \quad$ March 12, 1955

\section{Reversible Polarographic Reduction of Niobium}

THE polarographic reduction of niobium in concentrated hydrochloric acid ${ }^{1}$, and in oxalate and tartrate solutions (ref. 2 and Mrs. B. Lamb, private communication), has been shown to be due to reduction of $\mathrm{Nb}(\mathrm{V})$ to $\mathrm{Nb}(\mathrm{IV})$. Reductions in these media are, however, irreversible. Recent studies on the precipitation of niobium with tannic acid from

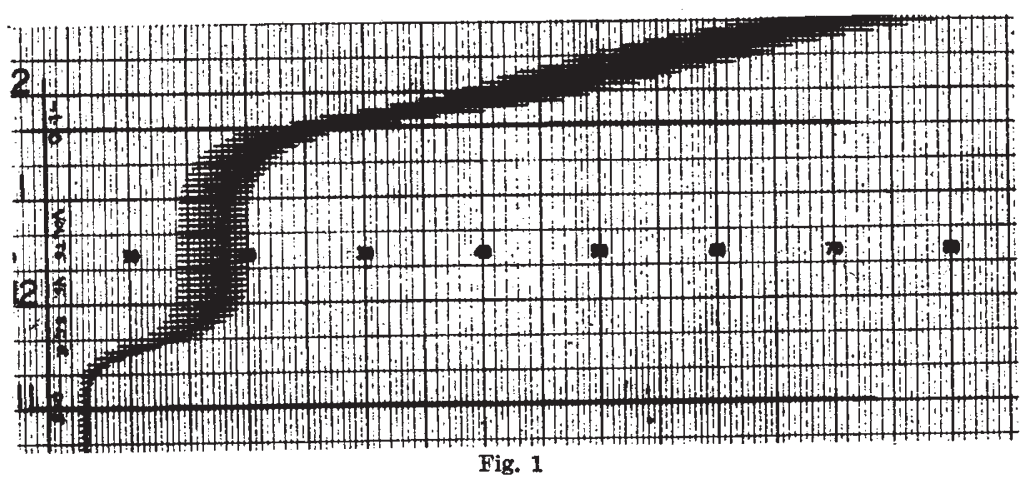

Fig. 1

various complexing solutions (G. W. C. Milner, G. A. Barnett and A. A. Smales, unpublished work) in this laboratory have indicated that niobium forms complexes with malic, citric, lactic and ethylenediaminetetra-acetic acids. We have found polarographic steps corresponding to the reduction of these complexes.

The reduction of niobium from solutions of the disodium salt of ethylenediamine-tetra-acetic acid

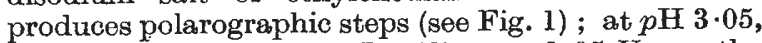
$E_{1 / 2}(1)=-0.609 \mathrm{~V} . ; E_{1 / 2}(2)=-\mathrm{I} \cdot 05 \mathrm{~V}$. vs. the saturated calomel electrode. The second step coalesces with the hydrogen wave and is difficult to measure with conventional polarographic equipment. The half-wave potential and reversibility (tested by measurement of the inverse slope of $E$ against $\log _{10} i /\left(i_{d}-i\right)$ plot) of the first wave varies with $p H$.

$\begin{array}{rlll}p H & \text { [EDTA] } & E_{1 / 2}(1) & \text { Slope } \\ 2.00 & 0.001 M & -0.419 & 0.060 \\ 3.05 & 0.1 M & -0.609 & 0.059 \\ 3.20 & 0.1 M & -0.613 & 0.062 \\ 3.40 & 0.1 M & -0.615 & 0.069 \\ 3.60 & 0.1 M & -0.657 & 0.072 \\ 4.05 & 0.1 M & -0.767 & 0.100 \\ 4.75 & 0.1 M & -0.835 & 0.086\end{array}$

(A slope of 0.059 corresponds to a reversible one-electron reduction.)

Studies in solutions at $p \mathrm{H} \mathbf{3} \cdot 20$ show that the leight of the first wave is proportional to the niobium concentration over the range $500-5 \mu \mathrm{gm} . / \mathrm{ml}$. The occurrence of two peaks when the Barker squarewave polarograph is used confirms the reversibility of the electrode reactions ${ }^{3}$, for the height of the peaks obtained is similar to that obtained from a thallium solution of the same molarity. The first of these peaks can be used as a measure of concentration and extends the limit at which niobium can be measured to $0.1 \mu \mathrm{gm} . / \mathrm{ml}$.

A fuller account of this work will be published elsewhere.

\section{J. FERRETT}

G. W. C. Mulner

Analytical Chemistry Group,

Atomic Energy Research Establishment, Harwell, Berks. Nov. 18.

${ }^{1}$ Cozzi, D., and Vivarelli, S., Ricerca sci., 23, 2244 (1953).

2 Elson, R. E., J. Amer. Chem. Soc., 75, 4193 (1953).

3 Ferrett, D. J., and Milner, G. W. C., Analust, [80, 132 (1955)].

\section{Inefficiency of Diphenylpicrylhydrazyl as a Radical Scavenger}

IN the quantitative study of a reaction proceeding by a radical mechanism, it is of prime importance to know accurately the rate of generation of radicals in the system. For this purpose, $\alpha, \alpha$-diphenyl- $\beta$-picrylhydrazyl has been used as a radical scavenger. This material is a free radical and has the structure $\left(\mathrm{C}_{6} \mathrm{H}_{5}\right)_{2} \mathrm{~N}$.N.C. $\mathrm{H}_{2}\left(\mathrm{NO}_{2}\right)_{3}$. It is stable itself but interacts with reactive radicals to give stable products; it has a strong purple colour and the rate of fading of this colour in solution has been used for measuring the rate of production of radicals in the solution ${ }^{1}$. Provided that the concentration of $\alpha, \alpha$-diphervl- $\beta$ picrylhydrazyl is not very small, the calculated rate of production of radicals is independent of its concentration. This result suggests that the scavenger captures all the radicals which are produced.

Azo-iso-butyronitrile is commonly used as a source of free radicals; its decomposition can be represented as : $\left(\mathrm{CH}_{3}\right)_{2} \mathrm{C}(\mathrm{CN}) \cdot \mathrm{N}: \mathrm{N} . \mathrm{C}(\mathrm{CN})\left(\mathrm{CH}_{3}\right)_{2} \rightarrow 2\left(\mathrm{CH}_{3}\right)_{2} \mathrm{C}(\mathrm{CN}) \cdot+\mathrm{N}_{2}$. The decomposition can be followed either by measurement of the nitrogen evolved or by the use of $\alpha, \alpha$-diphenyl- $\beta$-picrylhydrazyl ${ }^{1}$. The rate measured by the latter method is a little less than the rate measured from nitrogen evolution ${ }^{2}$. It appears that some of the radicals generated from the azo compound do not react with $\alpha, \alpha$-diphenyl- $\beta$-picrylhydrazyl but instead interact with one another to give stable products. Some of the papers presented at a recent meeting of the American Chemical Society dealt with this subject ${ }^{3}$.

It has now been proved by a direct method that $\alpha, \alpha$-diphenyl- $\beta$-picrylhydrazyl does not react with all the radicals produced during the decomposition of azo-iso-butyronitrile in benzene solution. If ${ }^{14} \mathrm{C}$ azo-iso-butyronitrile is used, it is possible to determine with accuracy the products resulting from radicals escaping the scavenger. A typical experiment can be summarized as follows : a mixture of $2 \cdot 7 \mathrm{mgm}$. ${ }_{14} \mathrm{C}$-azo-iso-butyronitrile and $39 \cdot 2 \mathrm{mgm}$. $\alpha, \alpha$-diphenyl$\beta$-picrylhydrazyl in $1.35 \mathrm{ml}$. benzene was kept at $60^{\circ}$ for $16 \mathrm{hr}$. in the complete absence of air; it was found afterwards that the solution contained $0 \cdot 15$ mgm. of tetramethylsuccinodinitrile formed by the combination of pairs of $\left(\mathrm{CH}_{3}\right)_{2} \mathrm{C}(\mathrm{CN})$. radicals. If the velocity constant for the first-order decomposition of azo-iso-butyronitrile at $60^{\circ}$ is $1.20 \times 10^{-5} \mathrm{sec}^{-1}$, the calculated weight decomposed is $1.35 \mathrm{mgm}$. Work on the decomposition of this substance in benzene and other inert solvents ${ }^{4}$ shows that other products are also formed from the radicals, and that for a decomposition performed under the conditions of this experiment $0.15 \mathrm{mgm}$. tetramethylsuccinodinitrile is equivalent to $0.40 \mathrm{mgm}$. azo-iso-butyronitrile. It appears, therefore, that the radicals from only 0.95 mgm. of the decomposed azo compound react with the nitrile, and that the scavenger reacts with only about 70 per cent of the radicals generated in the system.

It is also found that, when the azo compound is decomposed in the presence of styrene, some of the 